\title{
New Enzymatic Method for the Determination of Total Phenolic Content in Tea and Wine
}

\author{
Roberto Stevanato, * Sabrina Fabris, and Federico Momo
}

Department of Physical Chemistry, University of Venice, Dorsoduro 2137, 30123 Venice, Italy

\begin{abstract}
A new spectrophotometric enzymatic method for the determination of total phenol content in tea and wine has been developed. The method is based on the peroxidase-catalyzed oxidation, by hydrogen peroxide, of phenols to phenoxyl radicals, which can react with aromatic substrates to form intensely colored adducts. In comparison with the widely used Folin-Ciocalteu method, this method appears to be more specific and more rapid and as a whole is not affected by the common interfering substances such as ascorbate, citrate, and sulfite. Numerous samples of teas and wines were analyzed by using the new method, and the results compared with those obtained by using the Folin and scavenging of DPPH methods. The differences of the total phenols content found by applying the three methods are discussed in terms of the different specificities of the analytical basis.
\end{abstract}

KEYWORDS: Total polyphenols; enzymatic analysis; tea; wine

\section{INTRODUCTION}

It has been established, as a result of numerous studies, that a correlation exists between epidemiological states and diets rich in fresh fruits and vegetables, which contribute decisively to the reduction of the risk of cardiovascular diseases and some types of cancer $(1-5)$. The active components of the diet that contribute to these protective effects are the antioxidant nutrients, and more recent research emphasizes the important and additional role of the polyphenolic components of plants $(6-10)$.

In particular, it has been demonstrated that considerable antioxidant properties in vivo and in vitro have been found in wine and tea, the two most important beverages in the world containing considerable amounts of polyphenols (11-16); among the compounds displaying these properties is resveratrol, a stilbene with anticarcinogenic and antitumor properties (1719). The total phenolic content of food is therefore an important parameter of their antioxidant properties $(5,20)$. The usual determination of total polyphenolic content is achieved using the Folin-Ciocalteu procedure of Singleton $(21,22)$, which is also adopted by the European Communities for wine analysis (23). This method is based on the chemical oxidation of the reduced molecules by a mixture of the two strong inorganic oxidants phosphotungstic and phosphomolybdic acids.

The total polyphenol content is therefore currently determined on the basis of the nonspecific redox reactions, which can be affected by other nonphenolic reducing molecules present in the samples (24). All of the other analytical methods reported, and in particular the radical scavenging activity, highperformance liquid chromatography with ultraviolet-visible detection, chemiluminescence, and fluorescence methods, appear

* Author to whom correspondence should be addressed (fax 39412348594; e-mail roberto.stevanato@unive.it). to be expensive, time-consuming, and often not very suitable for routine determinations (25).

In the present study we propose a new enzymatic method for the determination of the total polyphenolic content in foods and beverages. In comparison with Folin, the enzymatic method offers the advantages of a briefer measuring period, a greater specificity toward the polyphenols, and the almost total absence of the common interferences.

The new method was applied to determine the total polyphenolic content of 12 teas and 39 Italian red and white wines. The results were compared with those obtained by applying the Folin and the 2,2-diphenyl-1-picrylhydrazyl (DPPH) radical scavenging methods (26).

\section{MATERIALS AND METHODS}

General Experimental Procedures. $\alpha(+)$-Catechin, DPPH, 4-aminoantipyrine, hydrogen peroxide, Folin-Ciocalteu reagent, and the other reagents were purchased from Sigma and were used without further purifications. Horseradish peroxidase (HRP) donor:hydrogen peroxide oxidoreductase, EC 1.11.1.7 type II, was supplied by Sigma also.

Spectrophotometric and electronic paramagnetic resonance (EPR) measurements were carried out by a Beckman DU 640 and a Bruker ER 200 D instrument, respectively.

All measurements were carried out in triplicate.

Folin-Ciocalteu Method. The total phenolic content (TPC) by the Folin-Ciocalteu reagent was carried out according to the procedure reported in the literature $(22-24)$ with the following variations that we verified do not change the final result. In a spectrophotometric cuvette, to an aliquot of $20 \mu \mathrm{L}$ of tea infusion or wine (eventually diluted 1:5) were added in succession $150 \mu \mathrm{L}$ of Folin-Ciocalteu reagent, 600 $\mu \mathrm{L}$ of a $15 \% \mathrm{Na}_{2} \mathrm{CO}_{3}$ solution, and distilled water to a $3000 \mu \mathrm{L}$ final volume. After $2 \mathrm{~h}$, the absorbance increase was measured at $784 \mathrm{~nm}$ and the concentrations of TPC, expressed as catechin equivalent (CE), were determined by a calibration curve graphed following the same 
Table 1. Teas Analyzed

\begin{tabular}{|c|c|c|c|c|}
\hline no. & product denomination & origin zone & amount per bag $(\mathrm{g})$ & notes \\
\hline 1 & Gunpowder green tea & Orient & loose & green tea blend \\
\hline 2 & Java green tea & Java & 2 & green tea blend \\
\hline 3 & green tea & China & 1.75 & green tea \\
\hline 4 & detheined green tea & China & 1.75 & detheined green tea blend \\
\hline 5 & biological green tea & Nigiri (southern India) & 1.75 & green tea blend \\
\hline 6 & green tea & Sri Lanka & loose & green tea by biological agriculture \\
\hline 7 & green tea pure & China & 1.3 & green tea \\
\hline 8 & biological green tea & China & 1.5 & green tea by biological agriculture \\
\hline 9 & Cape of Good Hope drink & South Africa & 2.5 & $\begin{array}{l}\text { rooibos tea (Aspalathus linearis) } \\
\text { by biological agriculture }\end{array}$ \\
\hline 10 & Yunnan Tou-cha The & China & loose & tea \\
\hline 11 & finest Assam tea & northern India & 2 & tea blend \\
\hline 12 & English Breakfast Tea blend & not reported & 2 & tea blend \\
\hline
\end{tabular}

procedure and using $\alpha(+)$-catechin as standard polyphenol. A molar absorbance of $17800 \mathrm{M}^{-1} \mathrm{~cm}^{-1}$ was adopted.

DPPH Scavenging Method. The scavenging effect of antioxidant molecules on the DPPH radical signal was evaluated by EPR measurements (26). In a typical determination, $100 \mu \mathrm{L}$ of $10 \mu \mathrm{M} \alpha(+)$-catechin in potassium phosphate buffer, $0.1 \mathrm{M}$ and $\mathrm{pH} 7.0$, was incubated for 12 min with $100 \mu \mathrm{L}$ of an ethanol solution of $250 \mu \mathrm{M}$ DPPH. The values of $\Delta h / h_{0}$, where $\Delta h$ is the decrease of the signal intensity and $h_{0}$ the intensity measured in the absence of $\alpha(+)$-catechin, graphed versus the $\alpha(+)$-catechin concentration give a straight line in the range concentration of 3-9 $\mu \mathrm{M}$. The determinations of the polyphenol content in beverage samples were carried out by diluting the samples until they reached this concentration range; the resulting values are expressed as catechin equivalent (CE).

EPR measurement conditions were as follows: magnetic field, 348.0 $\mathrm{mT}$; microwave power, $12 \mathrm{~mW}$; modulation, $0.25 \mathrm{mT}$; room temperature; sweep time, $200 \mathrm{~s}$.

Tea and Wine Samples. Eleven commercial green and not green teas from Camellia sinensis and one rooibos tea (sample 9) from Aspalatus linearis were investigated.

In Table 1, denominations, origins, packaging, and some notes obtained from the commercial packaging of the teas are reported. As shown, the powder amount per bag varies; furthermore, the suggested procedures for the infusion preparation depend on the manufacturing. To obtain comparable data, we adopted the following standard procedure:

One gram of tea powder was infused for $4 \mathrm{~min}$ in $100 \mathrm{~mL}$ of distilled water at the initial temperature of $95^{\circ} \mathrm{C}$. Subsequently, the infusions were filtered and immediately analyzed to prevent natural oxidations.

In the case of the wines, we analyzed 39 samples in all, 22 reds, 16 whites, and 1 rosato, purchased by stores or supplied by wine vaults. All measurements were carried out on wine samples from bottles that had just been uncorked.

All wines were DOC (denominazione di origine controllata, officially checked and approved), produced in five different zones of the Veneto region (Italy), as shown in Table 2, where year of production, alcoholic grade, and typology are also reported.

\section{RESULTS}

Enzymatic Method for Total Polyphenols Determination. The enzymatic method we propose for the total (poly)phenolic content determination takes inspiration from the classic Trinder reaction. In its original version, this method is used for the spectrophotometric determination of hydrogen peroxide and is widely applied to determine the $\mathrm{H}_{2} \mathrm{O}_{2}$ (27) also produced by a principal reaction, for example, catalyzed by an oxidase (28).

In the presence of peroxidase, hydrogen peroxide reacts with phenol(s) and 4-aminophenazone (4-AP), which is colorless, to give a colored compound, the absorbance of which is
Table 2. Wines Analyzed

\begin{tabular}{|c|c|c|c|c|c|}
\hline no. & denomination & color & $\begin{array}{c}\text { production } \\
\text { year }\end{array}$ & $\begin{array}{l}\text { alcoholic } \\
\text { grade (\%) }\end{array}$ & origin zone \\
\hline 1 & Bardolino Classico & red & 2001 & 12 & Bardolino \\
\hline 2 & Bardolino Classico & red & 2001 & 12 & Bardolino \\
\hline 3 & Bardolino Chiaretto & rosato & 2000 & 12 & Bardolino \\
\hline 4 & Cabernet & red & 2000 & 12.5 & Colli Berici \\
\hline 5 & Cabernet & red & 2000 & 12 & Colli Berici \\
\hline 6 & Cabernet & red & 2001 & 12 & Colli Berici \\
\hline 7 & Cabernet & red & 2001 & 12 & Colli Berici \\
\hline 8 & Cabernet Franc & red & 1997 & 13.5 & Colli Berici \\
\hline 9 & Cabernet Franc & red & 1998 & 13 & Colli Berici \\
\hline 10 & Cabernet Franc & red & 1999 & 12.5 & Colli Berici \\
\hline 11 & Cabernet Franc & red & 2000 & 14 & Colli Berici \\
\hline 12 & Cabernet Franc & red & 2001 & 14 & Colli Berici \\
\hline 13 & Cabernet Franc & red & 2002 & 14 & Colli Berici \\
\hline 14 & Cabernet Franc & red & 2000 & 12.5 & Lison-Pramaggiore \\
\hline 15 & Cabernet Sauvignon & red & 2001 & 12 & Garda \\
\hline 16 & Merlot & red & 2000 & 12.5 & Lison-Pramaggiore \\
\hline 17 & Merlot & red & 2000 & 12.5 & Colli Berici \\
\hline 18 & Merlot & red & 2001 & 12 & Colli Berici \\
\hline 19 & Merlot & red & 2001 & 12 & Colli Berici \\
\hline 20 & Recioto & red & 2000 & 12.5 & Valpolicella \\
\hline 21 & Tocai Rosso & red & 2001 & 12 & Colli Berici \\
\hline 22 & Amarone della Valpolicella & red & 1998 & 14 & Valpolicella \\
\hline 23 & Valpolicella Classico & red & 2001 & 12 & Valpolicella \\
\hline 24 & Bianco di Custoza & white & 2001 & 12 & Garda \\
\hline 25 & Chardonnay & white & 2001 & 11.5 & Colli Berici \\
\hline 26 & Chardonnay & white & 2001 & 12 & Colli Berici \\
\hline 27 & Chardonnay & white & 2001 & 11.5 & Colli Berici \\
\hline 28 & Gambellara & white & 2000 & 11.5 & Gambellara \\
\hline 29 & Gambellara & white & 2001 & 12 & Gambellara \\
\hline 30 & Gambellara Classico & white & 2001 & 12.5 & Gambellara \\
\hline 31 & Gambellara Classico & white & 1998 & 12 & Gambellara \\
\hline 32 & Gambellara Classico & white & 1999 & 12 & Gambellara \\
\hline 33 & Gambellara Classico & white & 2000 & 12 & Gambellara \\
\hline 34 & Gambellara Classico & white & 2001 & 12.5 & Gambellara \\
\hline 35 & Garganego & white & 2001 & 12 & Colli Berici \\
\hline 36 & Garganego & white & 2001 & 12 & Colli Berici \\
\hline 37 & Recioto di Soave Classico & white & 2000 & 12.5 & Soave \\
\hline 38 & Sauvignon & white & 2001 & 12 & Colli Berici \\
\hline 39 & Soave Classico & white & 2001 & 12 & Soave \\
\hline
\end{tabular}

proportional to the amount of $\mathrm{H}_{2} \mathrm{O}_{2}$ present in the sample, according to the following reaction (29):

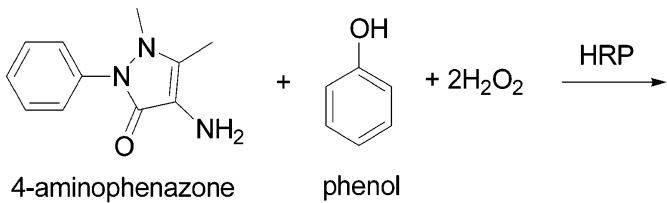<smiles>Cc1c(N=C2C=CC(=O)C=C2)c(=O)n(-c2ccc([14CH2][14CH2]O)cc2)n1C</smiles>

quinone-imine coloured product 


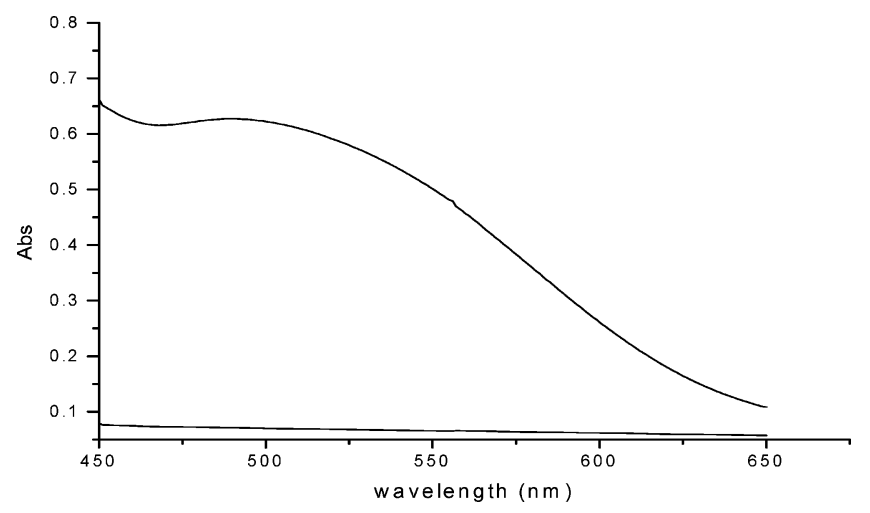

Figure 1. Visible spectra of solutions containing $3 \mathrm{mM} \mathrm{4-AP,} 2 \mathrm{mM} \mathrm{H}_{2} \mathrm{O}_{2}$, $0.33 \mu \mathrm{M} \mathrm{HRP}$, and $0.1 \mathrm{mM} \alpha(+)$-catechin in $0.1 \mathrm{M}$ potassium phosphate, $\mathrm{pH}$ 8.0, at room temperature: (lowest curve) without HRP; (highest curve) recorded 5 min after the start of the reaction.

On the basis of the reaction mechanism, the oxidized form of the enzyme, generated by the hydrogen peroxide, reacts with phenols, forming phenoxyl radicals, which, after diffusion from the active center of the enzyme, can react with further aromatic substrates (30). In the presence of a large excess of 4-AP, phenoxyl radicals rapidly react with the aromatic amine group, giving the quinone-imine colored product, characterized by high molar absorbance.

In general, little selectivity is shown by the enzyme; in fact, it has been found that a great number of phenols can act as aromatic donor molecules $(31,32)$. Also, flavonoids containing phenol $\mathrm{B}$ rings (33) and in general dietary polyphenols (34) can be oxidized by peroxidase $/ \mathrm{H}_{2} \mathrm{O}_{2}$ to give reactive aryloxy radicals.

In fact, it has been reported (29) that when the para-position of the phenol is occupied, the reaction with 4-AP takes place in the ortho-position. We confirmed these results by checking the peroxidase-catalyzed chromatic reaction with chemically different phenols substituted in the para-position (gallic acid, catechol, ferulic acid, vanillic acid, resveratrol, and $p$-cresol) and flavonoids (catechin, kaempferol, and quercetin). In all of these cases, an intense and permanent absorption band around $500 \mathrm{~nm}$ rapidly appears, similar to the one reported for catechin (Figure 1).

In particular, we observed that the molar absorbance value of the flavanol $\alpha(+)$-catechin, which presents two separated phenolic rings characterized by ortho and para free positions, is in agreement not only with that measured for the flavonols quercetin and kaempferol but also with the values obtained for phenols such as dimethylphenol or catechol, the molar absorbances of these substances ranging between 4500 and $5900 \mathrm{M}^{-1}$ $\mathrm{cm}^{-1}$. These data seem to indicate that each molecule can form only one phenoxyl radical, which is the fundamental step of the antioxidant properties of polyphenols, probably because the oxidized product, sometimes characterized by higher structural complexity, with more difficulty can lose further electrons.

From Figure 2, where the time courses of the colored compound formation at different catechin concentrations are reported, it appears that, under our experimental conditions, the reaction ends after $1 \mathrm{~min}$ at room temperature and up to 200 $\mu \mathrm{M}$ catechin concentration. Furthermore, the final absorbance values remain stable over $5 \mathrm{~min}$.

Under our experimental conditions, and in particular with reference to the above-reported reaction time, we verified that the $\mathrm{H}_{2} \mathrm{O}_{2}$-dependent horseradish peroxidase oxidation of $\alpha(+)$ catechin (35) appears to be negligible (data not shown).

Utilizing the data of Figure 2, recorded 2 min after the start of the reaction, a straight-line calibration graph was obtained in the range of $10-200 \mu \mathrm{M}$ catechin, characterized by a correlation coefficient of 0.9965 (insert of Figure 2). From this, a molar absorbance of $5900 \mathrm{M}^{-1} \mathrm{~cm}^{-1}$, using $\alpha(+)$-catechin as standard polyphenol, was calculated. Furthermore, no variation of the calibration graph was observed when absorbance values recorded at $5 \mathrm{~min}$ rather than $2 \mathrm{~min}$ were used.

The experimental data are reproducible when the usual experimental errors are taken into account, and the method appears to be rapid and suitable for the determination of dietary polyphenol contents in different samples, such as tea and wine.

In the wine sample analysis, we found that, with regard to the wine variety, the time reaction is longer than $1 \mathrm{~min}$, probably

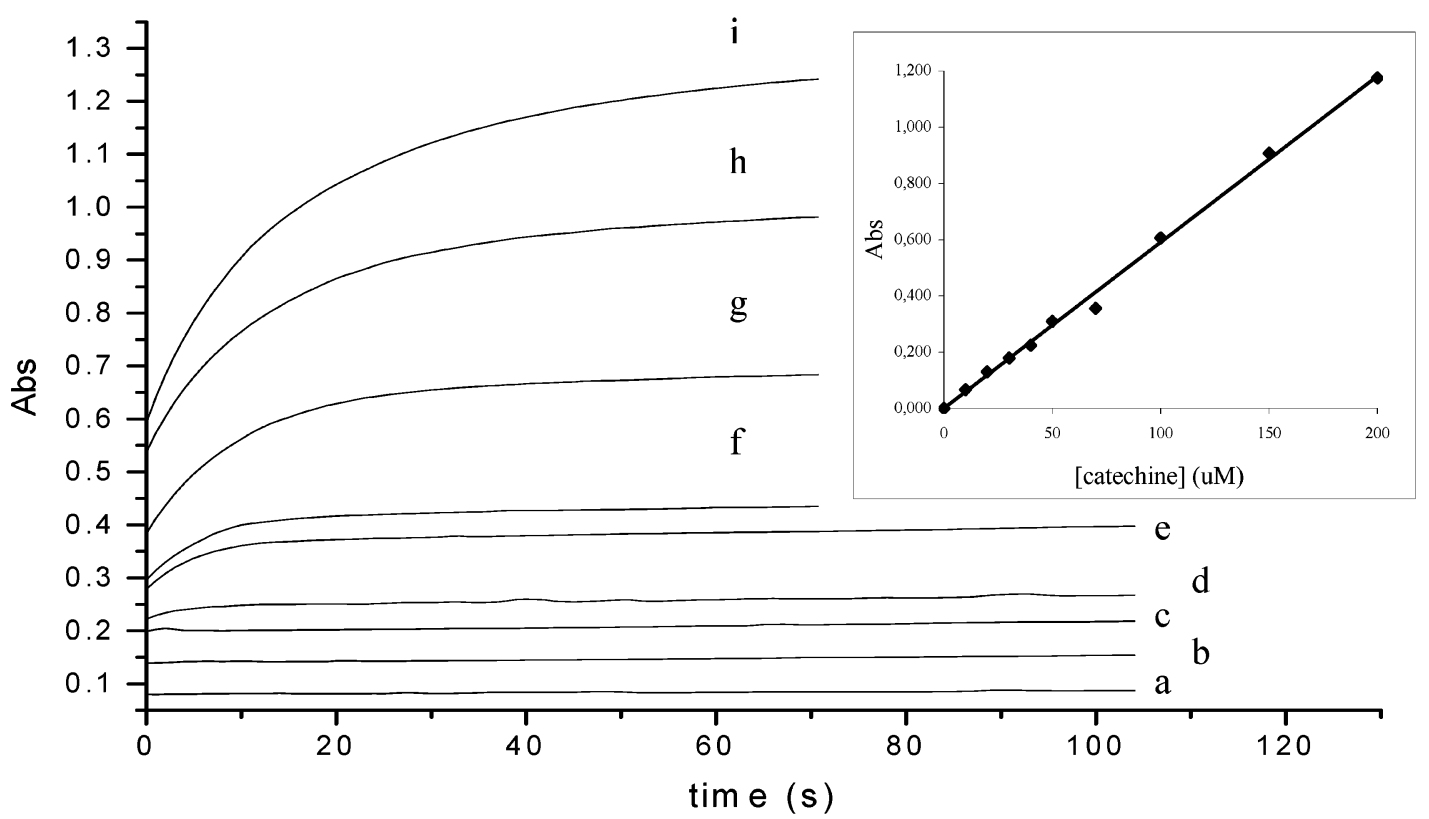

Figure 2. Time courses of the absorbance values recorded at $500 \mathrm{~nm}$ of solutions containing (a) no, (b) 10, (c) 20, (d) 30, (e) 50, (f) 70, (g) 100, (h) 150 , and (i) $200 \mu \mathrm{M} \alpha(+)$-catechin concentrations. Other experimental parameters were as in Figure 1. (Inset) Calibration graph for catechin determination using the previous data recorded 2 min after the start of the reaction $(r=0.9965)$. 

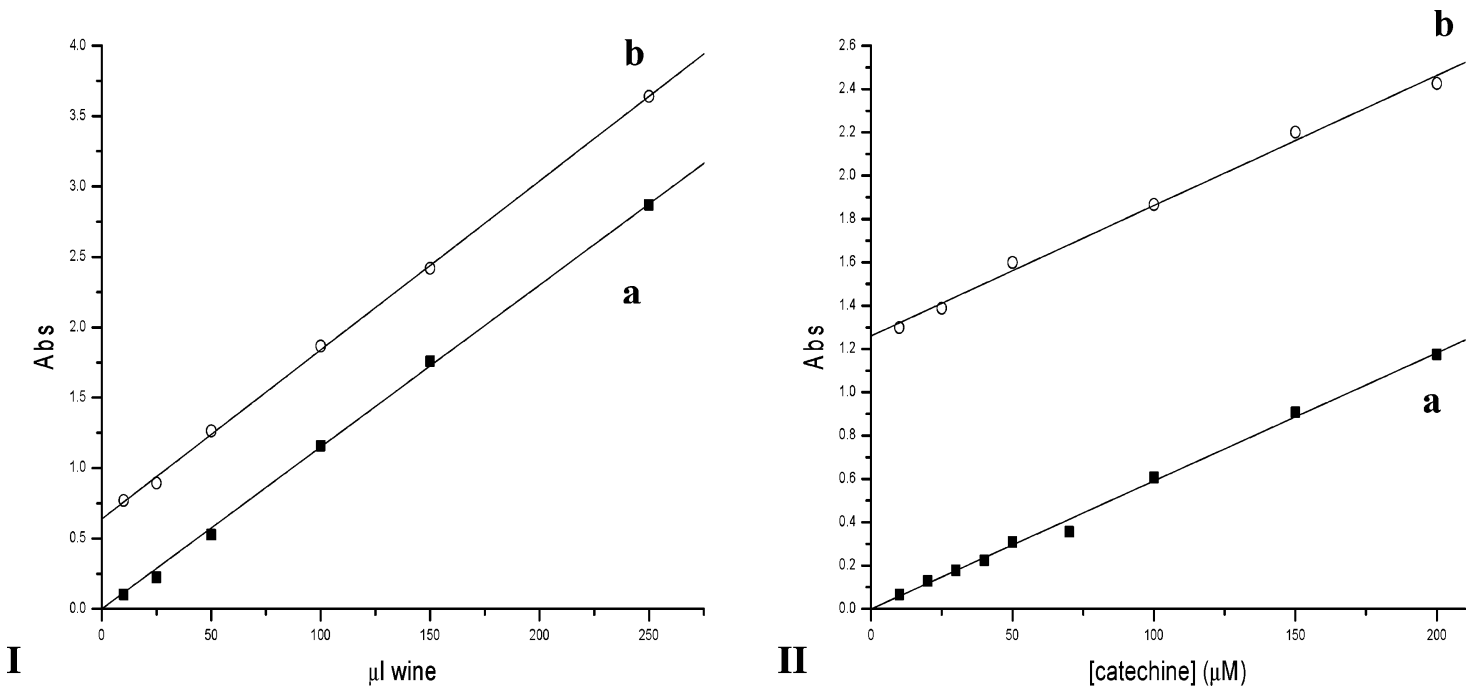

Figure 3. (I) Response linearity of the absorbance as a function of wine amount: (a) $3 \mathrm{mM} \mathrm{4-AP,} 2 \mathrm{mM} \mathrm{H}_{2} \mathrm{O}_{2}$, and $0.33 \mu \mathrm{M} \mathrm{HRP}$ in $0.1 \mathrm{M}$ potassium phosphate, pH 8.0, with different sample 6 wine amounts; (b) plus $100 \mu \mathrm{M}$ catechin. (II) Calibration graph of the catechin using (a) experimental data recorded $5 \mathrm{~min}$ after the start of the reaction and (b) plus $100 \mu \mathrm{L}$ of sample 6 red wine. In both cases, a $0.2 \mathrm{~cm}$ path length spectrophotometric cell was sometimes used to obviate the high absorbance values.

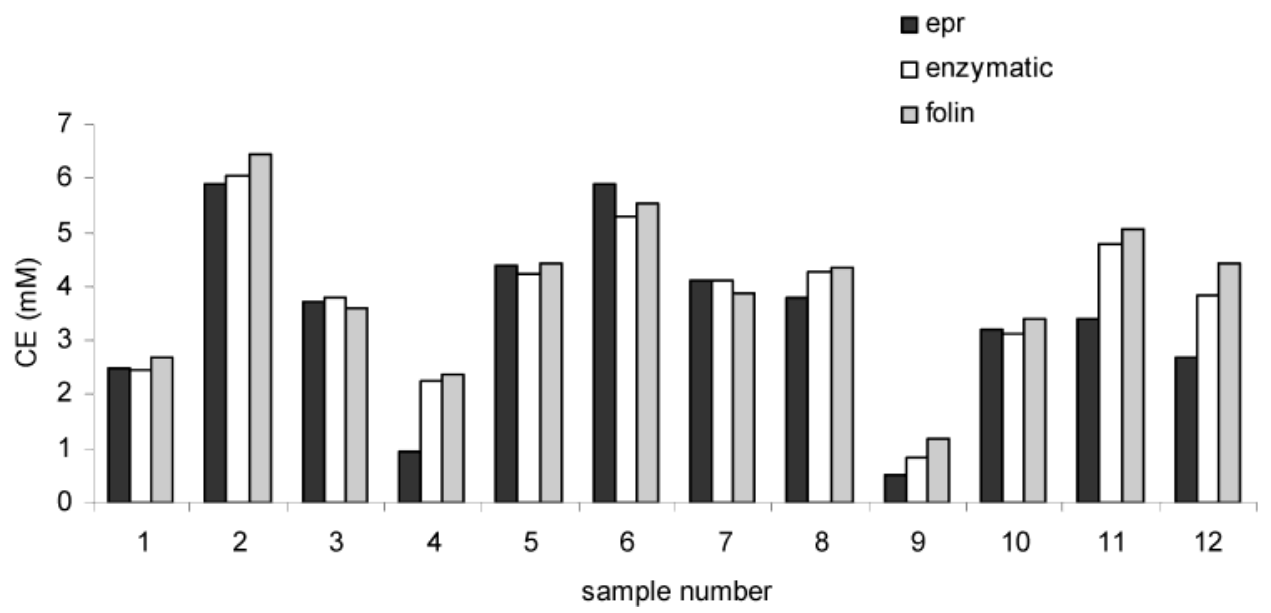

Figure 4. Total polyphenol content expressed as equivalent catechin of the tea infusions determined according to the EPR, enzymatic, and Folin methods. The reported values are the mean of triplicate experiments. The standard deviation was $<10 \%$ in all cases.

because the different polyphenols present in the real samples react with different rates as a consequence of the their chemical structures. After a number of experimental investigations, in which different red and white wines were used, a time of 5 min was adopted for the measure of the TPC. Furthermore, identical results were obtained using sodium perborate instead of hydrogen peroxide.

In a typical experiment, in a $3 \mathrm{~mL}$ spectrophotometric cell, $100 \mu \mathrm{L}$ of red wine or fresh tea infuse $(300 \mu \mathrm{L}$ of sample was used in the case of white wine) was added to a $0.1 \mathrm{M}$ potassium phosphate-buffered solution, $\mathrm{pH} 8.0$, containing $3 \mathrm{mM}$ 4-AP, 2 $\mathrm{mM} \mathrm{H}_{2} \mathrm{O}_{2}$, and $0.33 \mu \mathrm{M}$ HRP. The absorbance value was read at $500 \mathrm{~nm}$ after $5 \mathrm{~min}$, when the reaction was ended.

The response linearity was checked by measuring the absorbance value of solutions containing variable amounts of a red (sample 6) and a white (sample 28) wine in the ranges 10250 and $50-500 \mu \mathrm{L}$, respectively, also in the presence of known amounts of catechin.

In both cases, a straight line with a correlation coefficient of $>0.993$ was obtained (Figure 3). Furthermore, applying the above-reported experimental conditions, we verified that the catechin concentration range of the calibration graph (Figures 2 and 3 ) turns out to be suitable for the determination of the different $\mathrm{CE}$ values of all the samples we analyzed (teas and red and white wines).

As in the presence of enzyme inhibitors a deviation from linearity is expected, because the residual enzyme activity is not enough to catalyze the total conversion of the substrates within the fixed time; these results demonstrated that no enzyme inhibition by complex plant extracts takes place under our experimental conditions. Probably the possible natural proteins precipitating polyphenolics do not affect the peroxidase enzymatic activity owing to the dilution of the real sample.

In light of the above-reported results, we applied the enzymatic method proposed for the determination of the TPC in different samples of tea and wine and compared the results with those obtained by using the Folin-Ciocalteu (22) and quenching of the DPPH EPR signal methods (26). From the absorbance values obtained for real samples, utilizing the calibration graph of Figure 1, we can express the TPC as catechin equivalent molarity (CE).

Analysis of Teas. In Figure 4 are reported the amounts of TPC for the tested teas in terms of CE as obtained with the three methods.

From the experimental data, it is possible to state the following: 


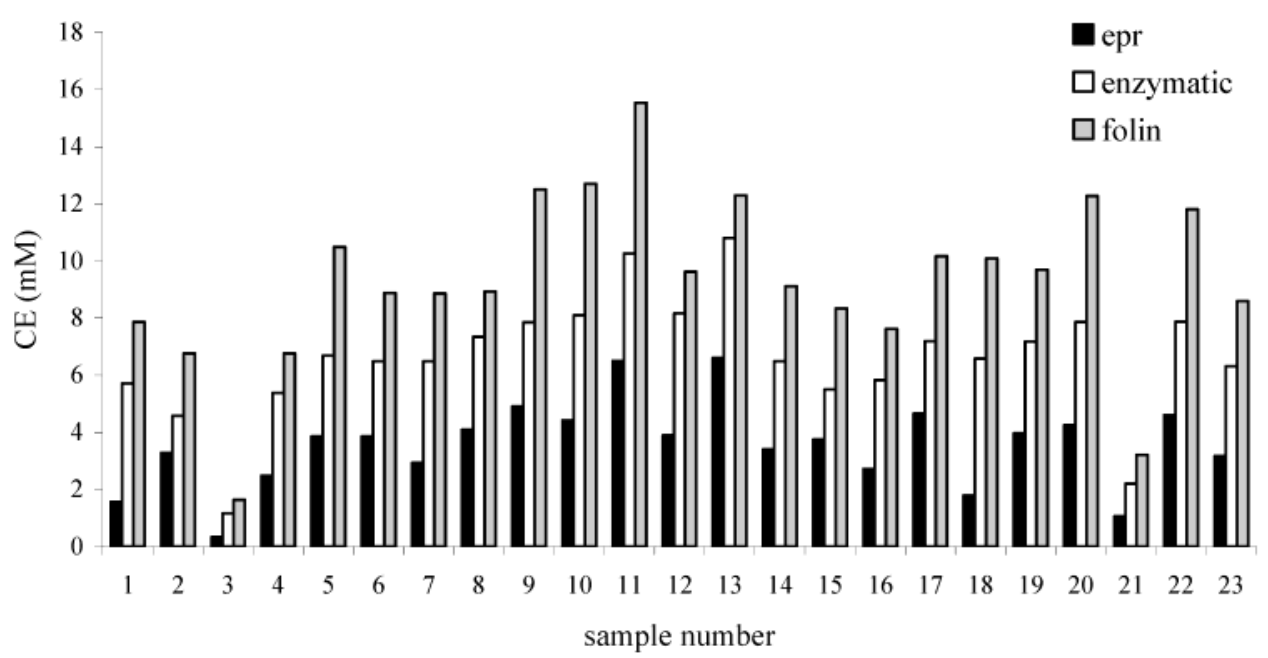

Figure 5. Total polyphenol content expressed as equivalent catechin of the red wines determined according to the EPR, enzymatic, and Folin methods. The reported values are the mean of triplicate experiments. The standard deviation was $<5 \%$ for the Folin method and $<2 \%$ for the other two methods.

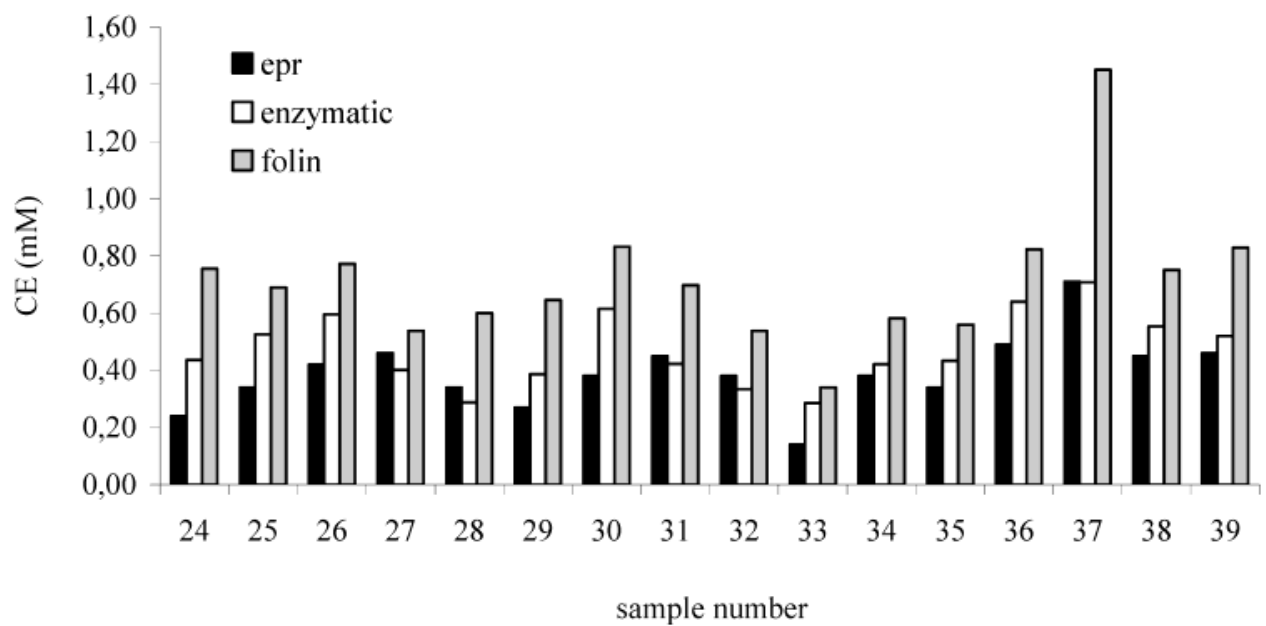

Figure 6. Total polyphenol content expressed as equivalent catechin of the white wines determined according to the EPR, enzymatic, and Folin methods. The reported values are the mean of triplicate experiments. The standard deviation was $<2 \%$ for all three methods.

(i) The different methods give an extraordinary equivalence of results, supporting the validity of the enzymatic method here proposed. Furthermore, a correlation coefficient of $>0.9$ was obtained by comparing the three series of data.

(ii) With the exception of the samples 4 and 9, all of the teas present a $\mathrm{CE}$ amount of polyphenols varying in the range of 3-6 mM. Furthermore, no significant difference is seen on the average $\mathrm{CE}$ value of green and nongreen teas, as is obvious by comparison of samples 10-12 with samples 5-8. These results indicate that the so-called "fermentation" in black tea induces biochemical transformations of tea flavonoids in theaflavins and thearubigens without modification of the overall antioxidant capacity of the infusion, according to previously reported results (36).

(iii) The lowest amount of CE of the samples 4 and 9 can be attributed to the particular nature of the beverage, that is, infusion of detheined tea in the first case and of Aspalathus linearis (rooibos) in the second.

Analysis of Wines. In Figures 5 and 6 the CE values for 23 red and 16 white Italian wines, respectively, analyzed by applying the three analytical methods, are reported.

From the two figures the following conclusions can be drawn:

(i) In the analysis of all the wines, the three methods give different results and, in particular, the CE values obtained by applying the Folin method appear to be generally higher than those obtained by the EPR method, whereas the enzymatic one gives intermediate results; that is, for the same sample it concludes that $\mathrm{CE}_{\mathrm{Folin}}>\mathrm{CE}_{\mathrm{enz}}>\mathrm{CE}_{\mathrm{ESR}}$.

(ii) Notwithstanding this, when the three series of data were compared, correlation coefficients ranging from 0.85 to 0.95 were obtained for red wines, whereas in the case of the white wines, the corresponding values vary between 0.70 and 0.81 .

(iii) Independently from the method used, the red wines show $\mathrm{CE}$ values about a magnitude of order higher than those relating to white ones, according to Dreosti (36).

(iv) The anomalous low values obtained for samples 21 and 3 are probably due to the particular vintage of these two wines, that is, a limited maceration time needed with grapes for the Tocai Rosso and the utilization of the white grape Garganega up to $15 \%$ of the total in the case of Bardolino Chiaretto, as indicated by the protocols of the DOC Italian wines (37).

(v) Different TPCs measured for the same variety of wine (i.e., Cabernet) of different years does not mean that we can attribute the behavior of the TPC to aging, even if a decrease of detectable polyphenols seems to appear, in particular, for samples 8-11. The aging, in fact, promotes the chemical oxidation of polyphenols to quinones and insoluble brown polymers (38).

Evaluation of Interferences. It has been reported that, between the nonphenolic compounds, ascorbate and sulfite are 
Table 3. TPC Values Obtained from the Analysis of Red Wine Sample 5 , Containing $3 \mathrm{mM}$ Interfering Substances, Applying the Folin and Enzymatic Methods (Data Are Expressed as Millimolar CE)

\begin{tabular}{lcccc} 
& \multicolumn{4}{c}{ interference } \\
\cline { 2 - 5 } method & none & ascorbic acid & citric acid & sulfite \\
\hline Folin & 7.0 & 9.7 & 7.9 & 7.8 \\
enzymatic & 5.2 & 5.3 & 5.3 & 4.9 \\
\hline
\end{tabular}

important potentially interfering substances on the TPC determination by the Folin-Ciocalteu method (24). Both contribute to increase the absorbance value, reacting with the Folin reagent and, if not correctly subtracted, give an overestimated TPC value.

We verified these interfering substances on the enzymatic method comparing the results with those obtained applying the Folin-Ciocalteu one. In particular, $3 \mathrm{mM}$ ascorbic acid, citric acid, or sulfite was added to a red wine sample, and the TPC values, expressed as $\mathrm{CE}$, were measured following the abovereported procedures (Table 3 ).

From the experimental data it appears that the enzymatic method is not affected by the presence of $3 \mathrm{mM}$ ascorbate or citrate, whereas a decrease of $\sim 6 \%$ in the $\mathrm{CE}$ content was found when $3 \mathrm{mM}$ sulfite was present in the wine. On the contrary, all three substances interfere with the TPC determination by the Folin method; in particular, the $\mathrm{CE}$ values increase $11 \%$ with sulfite, $13 \%$ with citrate, and $39 \%$ of ascorbate.

We also verified the contribution of the oxidation of red pigments present in red wine on the total absorbance of the chromatic reaction. In fact, the enzymatic oxidation of the anthocyanins, which show an absorbance maximum at $520 \mathrm{~nm}$, gives an optical density increase at $500 \mathrm{~nm}$. Comparing the initial rates at $500 \mathrm{~nm}$ of the peroxidase-catalyzed oxidation of the anthocyanins and of the chromatic reaction we propose, we found that the second is $\sim 10$ times higher than the first. The highest kinetic constant of the chromatic reaction and the large excess of 4-aminoantipyrine with respect to the anthocyanins in the reaction cell direct the reaction toward the chromatic one, and therefore the final absorbance value is mostly due to the analytic reaction. In conclusion, for this type of measurement, the error due to the red wine oxidation pigments appears to be negligible.

\section{DISCUSSION}

It is well-known that the antioxidant properties of the polyphenols are correlated with the delocalization, on the aromatic ring, of the phenoxyl unpaired electron, which stabilizes the free radical.

The peroxidase-catalyzed formation of the phenoxyl radicals and their quantification by the measure of the quinone-imine colored product, guaranteed by the specificity of the peroxidase toward the phenolic structures, appears to be a suitable measure of the antioxidant properties of polyphenols.

These considerations are supported by the extraordinary coincidence of $\mathrm{CE}$ values obtained for the green tea. These results indicate that all three methods measure the same substances present in the samples, which are catechins and their derivatives (26). On the other hand, the differences for the same sample of the $\mathrm{CE}$ values evidenced by the three methods in the case of the red and white wines, and partially also for nongreen tea, indicate a different specificity for different classes of substances. In fact, the Folin-Ciocalteu method is based on the oxidant power of phosphotungstic and phosphomolybdic acid to oxidize a great number of reduced substances present in the sample other than polyphenols, such as ascorbate and sulfite, which are not present in the tea samples.

Therefore, the method appears to be hardly specific, and a correct measure of the natural polyphenols present in the wines requires laborious pretreatments of the samples to eliminate the reducing interferences (24).

We compared the enzymatic method with the quenching of the DPPH EPR signal. Although a simpler similar spectrophotometric method, based on the quenching of DPPH absorbance, is available $(39,40)$, we adopted the magnetic resonance one as a comparison method because this different technique avoids the weaknesses of the spectrophotometry, such as the possible inaccuracy due to the turbidity of the sample or to the absorbance of the reaction products. In fact, the reduced DPPH at $518 \mathrm{~nm}$ has a molar absorbance which is $\sim 15 \%$ of that of nonreduced DPPH.

In the case of the method based on the quenching of the DPPH EPR signal, the monoelectronic redox reaction involved appears to be strictly correlated to the presence of three and, to a less extent, two free hydroxyl groups in the galloyl moiety attached to flavan-3-ol at the 3-position as well as the orthotrihydroxyl group in the B ring of catechins (26), whereas the meta-hydroxyl groups of the A ring are not involved in the decrease of the EPR signal. Therefore, polyphenols, which do not present the characteristics above-described, are not revealed by the EPR method, even if they present antioxidant activity. Furthermore, we found that the DPPH quenching redox reactions are not always quantitative reactions but are sometimes equilibrium reactions (data not published).

It must be stressed that the variation of the molar absorbance of the compounds, which, in principle, should lead to concentration errors, is actually lessened by the fact that wines and teas are mixtures of relatively stable compositions, as demonstrated empirically by the coherence of data produced by the Folin and enzymatic methods.

In conclusion, the above-reported considerations totally justify the $\mathrm{CE}$ values obtained by applying the proposed method to the wines analysis, which are intermediate between those of the nonspecific Folin method and those of the strictly specific EPR method, and support the reliability of the enzymatic method we proposed for the correct determination of total phenolic content.

\section{ACKNOWLEDGMENT}

We thank Giorgia Crestani and Laura Lovato for support in the laboratory analysis; we thank also the Cantine Bastianello Claudio and Cantina Dal Maso Luigino from Gambellara (Italy) for supplying selected bottles of wine for the purpose of this research.

\section{LITERATURE CITED}

(1) Ames, B. N. Dietary carcinogens and anticarcinogens. Science 1983, 221, 1256-1264.

(2) Namiki, M. Antioxidants/antimutagens in food. Crit. Rev. Food Sci. 1990, 29, 273-300.

(3) Osawa, T.; Namiki, M.; Kawakishi, S. Role of dietary antioxidants in protection against oxidative damage. Basic Life Sci. 1990, 52, 139-153.

(4) Bravo, L. Polyphenols: chemistry, dietary sources, metabolism, and nutritional significance. Nutr. Rev. 1998, 56 (11), 317-333.

(5) Eberhardt, M. V.; Lee, C. Y.; Liu, R. H. Antioxidant activity of fresh apples. Nature 2000, 405, 903-904. 
(6) Hertog, M. G. L.; Fesrens, E. J. M.; Hollman, P. C. H.; Katan, M. B.; Kromhout, D. Dietary antioxidant flavonoids and risk of coronary heart disease: the Zutphen Elderly study. Lancet $\mathbf{1 9 9 3 ,}$ 342, 1007-1011.

(7) Vinson, J. A. Flavonoids in food as in vitro and in vivo antioxidants. Adv. Exp. Med. Biol. 1998, 439, 151-164.

(8) Yang, C. S.; Landau, J. M.; Huang, M. T.; Newmark, H. L. Inhibition of carcinogenesis by dietary polyphenolic compounds. Annu. Rev. Nutr. 2001, 21, 381-406.

(9) Sun, A. Y.; Simonyi, A.; Sun, G. Y. The "French paradox" and beyond: neuroprotective effects of polyphenols $(1,2)$. Free Radical Biol. Med. 2002, 32 (4), 314-318.

(10) Dragsted, L. O. Antioxidant actions of polyphenols in humans. Int. J. Vitam. Nutr. Res. 2003, 73 (2), 112-119.

(11) Ruch, R. J.; Cheng, S. J.; Klaunig, J. E. Prevention of cytotoxicity and inhibition of inytracellular communication by antioxidant catechins isolated from Chinese green tea. Carcinogenesis 1989, 10 (6), 1003-1008.

(12) Serafini, M.; Ghiselli, A.; Ferro-Luzzi, A. Red wine, tea and antioxidants. Lancet 1994, 344, 626.

(13) Soleas, G. J.; Diamandis, E. P.; Goldberg, D. M. Wine as a biological fluid: history, production, and role in disease prevention. J. Clin. Lab. Anal. 1997, 11 (5), 287-313.

(14) von Gadow, A.; Joubert, E.; Hansmann, C. F. Comparison of the antioxidant activity of rooibos tea (Aspalatus linearis) with green, oolong and black tea. J. Agric. Food Chem. 1997, 45, 73-77.

(15) Rechner, A. R.; Wagner, E.; Van Buren, L.; Van De Put, F.; Wiseman, S.; Rice-Evans, C. A. Black tea represents a major source of dietary phenolic among regular tea drinkers. Free Radical Res. 2002, 36 (10), 1127-1135.

(16) Greenrod, W.; Fenech, M. The principal phenolic and alcoholic components of wine protect human lymphocytes against hydrogenperoxide- and ionizing radiation-induced DNA damage in vitro. Mutagenesis 2003, 18 (2), 119-126.

(17) Jang, M.; Cai, L.; Udeani, G. O.; Slowing, K. V.; Thomas, C. F.; Beecher, C. W. W.; Fong, H. H. S.; Farnsworth, N. R.; Kinghorn, A. D.; Mehta R. G.; Moon, R. C.; Pezzuto, J. M. Cancer chemoprotective activity of resveratrol, a natural product derived from grapes. Science 1997, 275, 218-220.

(18) Falchetti, R.; Fuggetta, M. P.; Lanzilli, G.; Tricarico, M.; Ravagnan, G. Effects of resveratrol on human immune cell function. Life Sci. 2001, 70 (1), 81-96.

(19) Burns, J.; Yokoya, T.; Ashihara, H.; Lean, M. E.; Crozier, A. Plant food and herbal sources of resveratrol. J. Agric. Food Chem. 2002, 50, 3337-3340.

(20) Wang, H.; Cao, G.; Prior, R. L. Total antioxidant capacity of fruits. J. Agric. Food Chem. 1996, 44, 701-705.

(21) Singleton, V. L.; Rossi, J. A. Colorimetry of total phenolics with phosphomolybdic and phosphotungstic acid reagents. Am. J. Enol. Vitic. 1965, 16, 144-147.

(22) Di Stefano, R.; Guidoni, S. The analysis of total polyphenols in musts and wines. Vignevini 1989, 1 (2), 47-52.

(23) Folin-Ciocalteu Index. Off. J. Eur. Communities 1992, 178179.

(24) Singleton, V. L.; Orthofer, R.; Lamuela-Raventòs, R. M. Analysis of total phenols and other oxidation substrates and antioxidants by means of Folin-Ciocalteu reagent. Methods Enzymol. 1999, 299, 152-178.
(25) Beecher, G. R.; Warden, B. A.; Merken, H. Analysis of tea polyphenols. Proc. Soc. Exp. Biol. Med. 1999, 220 (4), 267270.

(26) Nanjo, F.; Goto, K.; Seto, R.; Suzuki, M.; Sakai, M.; Hara, Y. Scavenging effects of tea catechins and their derivatives on 1,1diphenyl-2-picrylhydrazyl radical. Free Radical Biol. Med. 1996, 21 (6), 895-902.

(27) Vojinovìc, V.; Azevedo, A. M.; Martins, V. C. B.; Cabral, J. M. S.; Gibson, T. D.; Fonseca, L. P. Assay of $\mathrm{H}_{2} \mathrm{O}_{2}$ by HRP catalysed co-oxidation of phenol-4-sulphonic acid and 4-aminoantipyrine: characterization and optimisation. J. Mol. Catal. B: Enzymol. 2004, 28, 129-135.

(28) Barham, D.; Trinder, P. An improved color reagent for the determination of blood glucose by the oxidase system. Analyst 1972, 97 (151), 142-145.

(29) Fiamegos, Y. C.; Stalikas, C. D.; Pilidis, G. A.; Karayannis, M. I. Synthesis and analytical applications of 4-aminopyrazolone derivatives as chromogenic agents for the spectrophotometric determinations of phenols. Anal. Chim. Acta 2000, 403, 315323.

(30) Van Deurzen, M. P. J.; van Rantwijk, F.; Sheldon, R. A. Selective oxidations catalyzed by peroxidases. Tetrahedron 1997, 53 (39), 13183-13220.

(31) Adam, W.; Lazarus, M.; Saha-Moller, C. R.; Weichold, O.; Hoch, U.; Haring, D.; Schreier, P. Biotransformation with peroxidases. Adv. Biochem. Eng. Biotechnol. 1999, 63, 73-108.

(32) Veitch, N. C.; Smith, A. T. Horseradish peroxidase. Adv. Inorg Chem. 2001, 51, 107-162.

(33) Chan, T.; Galati, G.; O'Brien, P. J. Oxygen activation during peroxidase catalysed metabolism of flavones or flavanones. Chem. Biol. Interact. 1999, 122, 15-25.

(34) Galati, G.; Sabzevari, O.; Wilson, J. X.; O’Brien, P. J. Prooxidant activity and cellular effects of the phenoxyl radicals of dietary flavonoids and other polyphenolics. Toxicology 2002, 177, 91104.

(35) Hosny, M.; Rosazza, J. P. N. Novel oxidation of (+)-catechin by horseradish peroxidase and laccase. J. Agric. Food Chem. 2002, 50, 5539-5545.

(36) Dreosti, I. E. Antioxidant polyphenols in tea, cocoa, and wine. Nutrition 2000, 16 (7-8), 692-694.

(37) Associazione Nazionale Sommelier. Enografia Nazionale; Bersani, Ed.; Reggio Emilia, 1996; Vol. 2.

(38) Macheix, J.-J.; Sapis, J.-C.; Fleuriet. A. Phenolic compounds and polyphenoloxidase in relation to browning in grapes and wines. Crit. Rev. Food Sci. Nutr. 1991, 30 (3), 441-486.

(39) Ancerewicz, J.; Migliavacca, E.; Carrupt, P. A.; Tersta, B.; Brée, F.; Zini, R.; Tillement, J. P.; Labidalle, S.; Guyot, D.; ChauvetMonges, A. M.; Crevat, A.; Le Ridant, A. Structure-property relationships of trimetazidine derivatives and model compounds as potential antioxidants. Free Radical Biol. Med. 1998, 25 (1), 113-120.

(40) Basly, J. P.; Marre-Fournier, F.; Le Bail, J. C.; Habrioux, G.; Chulia, A. J. Estrogenic/antiestrogenic and scavenging properties of (E)- and (Z)-resveratrol. Life Sci. 2000, 66 (9), 769-777.

Received for review January 20, 2004. Revised manuscript received June 25, 2004. Accepted July 7, 2004.

JF049898S 